\title{
S-ALLELE SPECIFICITY OF STIGMA PROTEINS IN BRASSICA OLERACEA AND B. CAMPESTRIS
}

\author{
KOKICHI HINATA and TAKESHI NISHIO \\ Faculty of Agriculture, Tohoku University, Sendai, Japan
}

Received 2.ii.78

\begin{abstract}
SumMARY
Correlation was demonstrated between $S$ alleles and differential stigma proteins separated by isoelectric focusing. Taking seven $S$-segregating families in $B$. oleracea and $B$. campestris, the differential proteins of individuals were analysed, and at the same time their $S$ genotypes were determined from the data on pollen tube penetrations in intra-family diallel pollinations. Self-incompatibility was controlled sporophytically by a pair of $S$ alleles. All but two of the differential protein bands were completely correlated with $S$ alleles, and all of them were prominently PAS positive. The content of an $S$-correlated protein in the stigma of homozygotes was estimated to be roughly twice as much as that in heterozygotes. Of thirteen $S$ alleles investigated, two being identical, seven were correlated with distinct glycoproteins; no differential proteins were detected associated with the other six. The $S$-correlated glycoproteins were postulated to be the specific products of $S$ alleles.
\end{abstract}

\section{INTRODUCTION}

Genetrc studies have revealed that self-incompatibility in Cruciferae is characterised by sporophytic control of multiple $S$ alleles (Bateman, 1955; Thompson, 1957; Haruta, 1962). In legitimate pollinations, pollen grains germinate on the stigma and grow through the pectin-cellulose layer of stigmatic papillae (Kroh, 1964). In illegitimate pollinations, pollen grains rarely germinate on the stigma, and when they do the pollen tubes stop at the pectin-cellulose layer (Kanno and Hinata, 1969; Dickinson and Lewis, 1973). The stigmatic surface is considered to be the recognition site between pollen and pistils in self-incompatibility response. Presence of $S$-specific antigens in stigmas was indicated by immunological methods (Nasrallah and Wallace, 1967; Nasrallah, 1974; Sedgley, 1974a, $b$; Kučera and Polák, 1975) and by disc electrophoresis (Nasrallah et al., 1970). Correlations between three $S$ alleles and the antigens or disc electrophoretic bands were studied by Nasrallah et al. (1972).

It has been shown in our studies of different $S$ homozygotes in $B$. olerace $a$ and $B$. campestris that stigmatic homogenates contain differential proteins which are detected by acrylamide-gel isoelectric focusing. The differential bands are found in mature stigmas but not in young stigmas, ovaries, styles, leaves or seedlings. They are PAS positive and react with concanavalin A. It has been postulated that the differential protein bands are $S$-allele specific (Nishio and Hinata, 1977a and $b, 1978$ ).

The present study was undertaken to investigate the $S$ specificity of the differential proteins on various materials. Taking wild plants as the main material, the segregations of $S$ alleles and of stigmatic proteins were investigated in parallel, and their relations were discussed. 


\section{MATERials AND METHODS}

Seeds of $B$. oleracea L. ssp. robertiana were collected at Cabo Norfeo near Rosas, Spain, in 1975. B. campestris L. was collected from a naturalised population at Oguni, Yamagataken, Japan, in 1973. Selfed seeds were obtained by bud pollination from several plants grown in a glass house in the laboratory. Five selfed families were raised from the former species (O-171-2, -7, -15,-18 and -23) and one from the latter (C-470-30). In addition, one $\mathrm{F}_{2}$ family $\left(S_{13}-S_{22}\right)$ was raised by bud pollination from an $\mathrm{F}_{1}$ hybrid of oleracea homozygotes of determined $S$-type. The original seeds were provided from Dr. N. P. A. van Marrewijk, Institute for Horticultural Plant Breeding, The Netherlands. Diallel or test-cross pollination was carried out in each family, and the pollen tube behaviour was examined on the following day with the aid of fluorescent microscopy after aniline blue staining (Nakanishi and Hinata, 1973). Score ++ was given for crosses in which abundant pollen tubes penetrated stigmatic tissues; score +, where many pollen tubes penetrated while many others failed; score \pm , where $<20$ pollen tubes penetrated a stigma; and score - , where penetrating tubes were absent or less than five per stigma. Observations were generally replicated several times for each cross combination when irregular data were obtained. From these data $S$ genotype was inferred in every plant of a family.

Twenty stigmas in oleracea or 25 in campestris were collected from open flowers of each plant before anther dehiscence. The isoelectric focusing of stigma proteins was performed by the method described in a previous paper (Nishio and Hinata, 1978). The gels after electric focusing were immersed in 12.5 per cent trichloroacetic acid for 1 night, and washed in 7.0 per cent acetic acid with 4-5 changes for 1 week to remove ampholine. After this procedure the gels were stained for 45 minutes with 0.2 per cent Coomassie Brilliant Blue G 250 in acetic acid/ethanol/water (10:45:45), destained in acetic acid/ethanol/water $(10: 25: 65)$, and then stored in 7.0 per cent acetic acid. Stained gels were scanned by a densitometer at $570 \mathrm{~nm}$. Carbohydrate localisation on the gels was detected by the periodic acid Schiff (PAS) reaction according to Zacharius et al. (1969).

\section{Results}

All the families showed segregation in their pollen tube behaviour. The general segregation pattern of incompatibility was explicable by the sporophytic action of $S$ alleles, and the $S$ genotype of every plant was inferred from the diallel pollination tables. The observed families were classified to three cases.

\section{(i) Families 0-171-23 and $F_{2} \mathrm{~S}_{13}-\mathrm{S}_{22}$}

In these families, each $S$ allele was correlated with one or more differential protein bands. An example is family O-171-23. From the diallel crosspollinations of 20 plants in the family, six plants were inferred to be $S_{a} S_{a}$, two plants $S_{b} S_{b}$ and 12 plants $S_{a} S_{b}$ as illustrated at the left side in fig. la. Here $S_{a}, S_{b}$ were arbitrarily used to distinguish homozygotes of two $S$ alleles and heterozygotes. The diallel table was in accordance with sporophytic co-dominance reactions of $S$ alleles, with the exceptions of plants nos. 5,7 and 18 where $S_{a}$ was dominant over $S_{b}$ in stigmas. 
Presence or absence of differential bands is shown at the right side of fig. la. Without exception, $S_{a}$ homozygotes had the $\mathrm{B}_{3}$ band, $S_{b}$ homozygotes had $B_{1}$ and $B_{2}$, and their heterozygotes and parent plant had all three. Densitometric scans of representative gels are illustrated in fig. $1 \mathrm{~b}$. All the three bands were shown to be PAS positive. These demonstrate

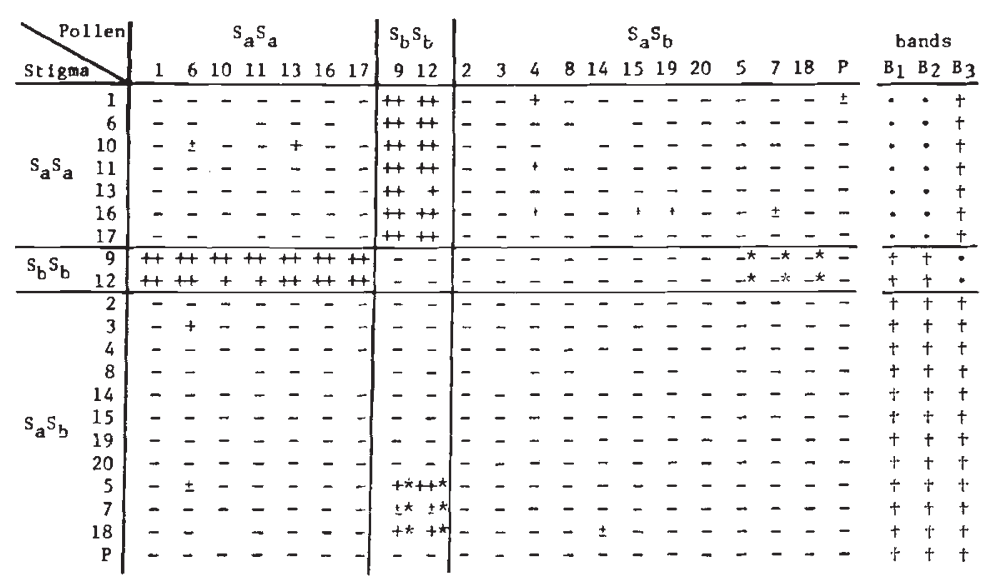

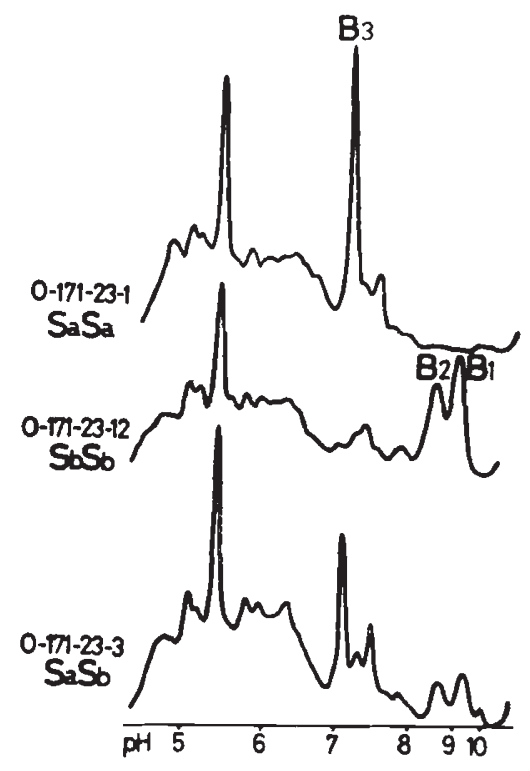

Fig. 1.-Data of the diallel pollinations in family, 0-171-23 (fig. 1a, left) and the presence $(\dagger)$ or absence $($.$) of differential bands in each plant (fig. 1a, right), and the densi-$ tometries of the stained gels of representative plants (fig. lb). Score ++ , abundant pollen tubes penetrating; + , many pollen tubes penetrating but some failed;,$\pm<20$ pollen tubes penetrating;,$-<5$ or no pollen tubes penetrating. S-genotypes $\left(S_{a} S_{a}\right.$, $S_{b} S_{b}$, etc.) were assigned to the plants of each mating group assuming a 1-locus sporophytic system with co-dominance. * are exceptional cases where $S_{a}$ is dominant to $S_{b}$ in stigmas only. $\mathrm{P}$ denotes the parent plant vegetatively propagated. 
that the $\mathrm{B}_{3}$ glycoprotein is associated with the $S_{a}$ allele and $\mathrm{B}_{1}$ and $\mathrm{B}_{2}$ glycoproteins with the $S_{b}$ allele.

The area under the densitometer tracing of Coomassie Blue staining was shown to be proportional to the amount of protein (Fazekas de St Groth et al., 1963). The peak area of a differential protein band was approximated to a triangle and the protein content was estimated from a standard curve which was made using bovin serum albumin. Fig. 2 shows protein contents per 20 stigmas estimated on the bands $B_{1}, B_{2}$ and $B_{3}$ in the family O-171-23,
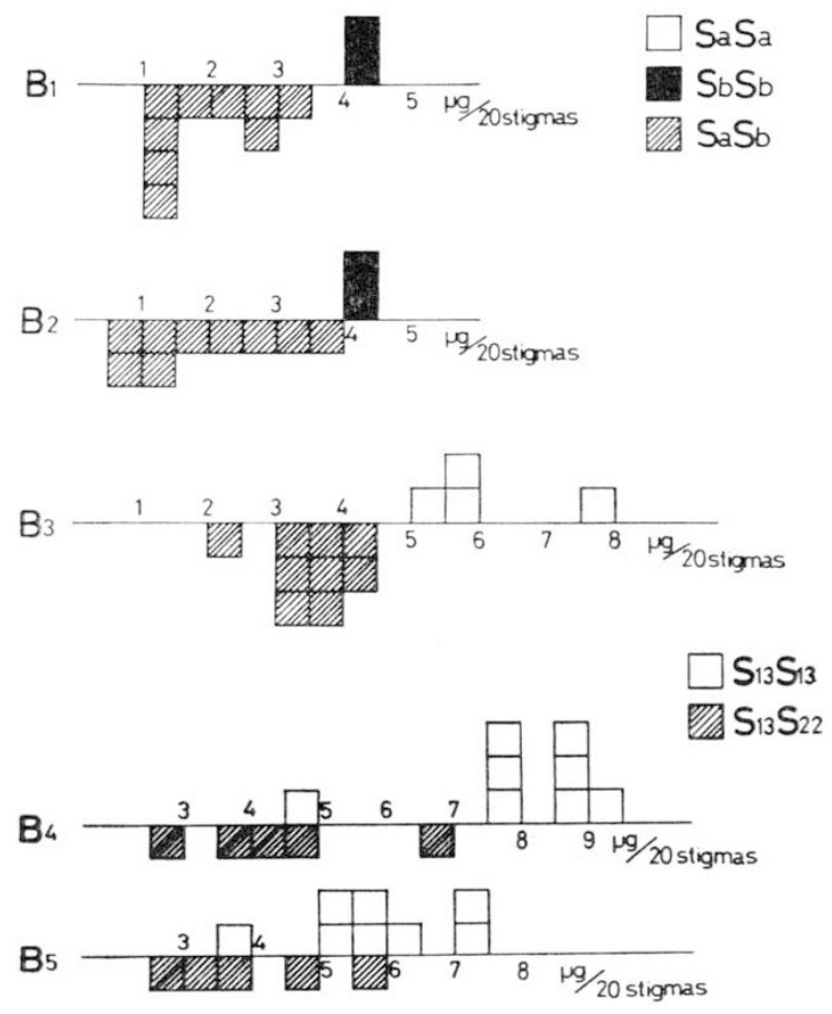

FIG. 2.-Estimated protein contents of differential bands in 20 stigmas of each plant in family O-171-23 $\left(\mathrm{B}_{1}, \mathrm{~B}_{2}\right.$ and $\left.\mathrm{B}_{3}\right)$ and in an $\mathrm{F}_{2}$ family $S_{13}-S_{22}\left(\mathrm{~B}_{4}\right.$ and $\left.\mathrm{B}_{5}\right)$. Each square represents 1 plant.

and on $\mathrm{B}_{4}$ and $\mathrm{B}_{5}$ in an $\mathrm{F}_{2}$ family $S_{13}-S_{22}$, where the bands $\mathrm{B}_{4}$ and $\mathrm{B}_{5}$ were ascribed to the $S_{13}$ allele and corresponded to the respective bands $h$ and $g$ in a previous report (Nishio and Hinata, 1977a). The band ascribed to $S_{22}$ was not examined due to a technical failure. The estimation was replicated only once or twice in each plant according to the amount of material available. Although the band protein content of individual plants was variable, the average protein content of homozygotes was found to be significantly higher than that of heterozygotes, in every band. The ratio of the average value of homozygotes to that of heterozygotes was $2 \cdot 24$, $2 \cdot 17,1 \cdot 70,1 \cdot 82$ and 1.41 for $B_{1}, B_{2}, B_{3}, B_{4}$ and $B_{5}$, respectively. 
(ii) Family 0-171-7

The diallel pollination of this family indicates that all plants were selfincompatible and that two $S$ alleles segregated (fig. 3a). However, the isoelectric focusing of each plant did not reveal any protein band differences (fig. 3b). No prominent PAS positive band was found in any gel. This indicates that the $S_{g}$ and $S_{h}$ alleles produce amounts of proteins too small to be detected or that they do not produce any specific proteins.

\begin{tabular}{|c|c|c|c|c|c|c|c|c|c|c|c|c|c|c|c|c|c|}
\hline \multirow{2}{*}{\multicolumn{2}{|c|}{ Stigma }} & $s_{g} s_{g}$ & & & ${ }_{h}^{5}$ & & \multicolumn{11}{|c|}{$\mathrm{S}_{\mathrm{B}} \mathrm{s}_{\mathrm{h}}$} \\
\hline & & 2161 & & 5 & 8 & 18 & $I$ & 3 & 6 & 7 & 9 & 10 & 11 & 121 & 131 & 14 & 15 \\
\hline \multirow{3}{*}{$\mathrm{s}_{\mathrm{g}} \mathrm{s}_{\mathrm{g}}$} & 2 & -- & -1 & + & + & + & + & + & + & +4 & + & + & + & ++ & \pm+ & + & + \\
\hline & 16 & $-\quad-$ & - & + & + & + & + & + & + & + & $H$ & + & + & + & ++ & + & + \\
\hline & 17 & $-\quad-$ & -1. & H & + & + & + & + & + & + & + & + & + & ++ & $+t$ & + & + \\
\hline \multirow{3}{*}{$S_{h} S_{h}$} & 5 & +++ & & - & - & - & - & - & - & - & - & - & - & - & - & - & - \\
\hline & 8 & +++ & & - & - & - & - & - & - & - & - & - & - & - & - & - & - \\
\hline & 18 & +++ & & $=$ & - & - & - & - & - & - & - & - & - & - & - & - & - \\
\hline \multirow{11}{*}{$s_{8} S_{h}$} & 1 & -- & - & - & - & - & - & - & - & - & - & - & - & - & - & - & - \\
\hline & 3 & $-\quad-$ & - & - & - & -1 & - & - & - & - & - & - & \pm & - & - & - & - \\
\hline & 6 & $-\quad-$ & \pm & - & - & \pm & - & - & - & - & - & + & \pm & - & - & \pm & - \\
\hline & 7 & $-\quad-$ & - & - & - & - & - & - & - & - & - & - & - & - & - & - & - \\
\hline & 9 & $-\quad-$ & - & - & - & - & - & - & - & - & - & - & - & - & - & - & - \\
\hline & 10 & - & - & - & - & - & - & - & - & - & - & - & - & - & - & - & - \\
\hline & 11 & $-\quad-$ & - & - & - & - & - & - & - & - & - & - & - & \pm & - & - & - \\
\hline & 12 & $-\quad-$ & - & - & - & -1 & - & - & - & - & - & - & - & - & - & - & - \\
\hline & 13 & $-\quad-$ & - & - & - & \pm & - & - & - & - & - & - & \pm & \pm & - & \pm & - \\
\hline & 14 & $-\quad-$ & \pm & - & - & - & - & - & - & - & - & - & - & - & - & - & - \\
\hline & 15 & $-\quad-$ & - & - & - & -1 & \pm & - & - & - & - & - & - & - & - & - & - \\
\hline
\end{tabular}

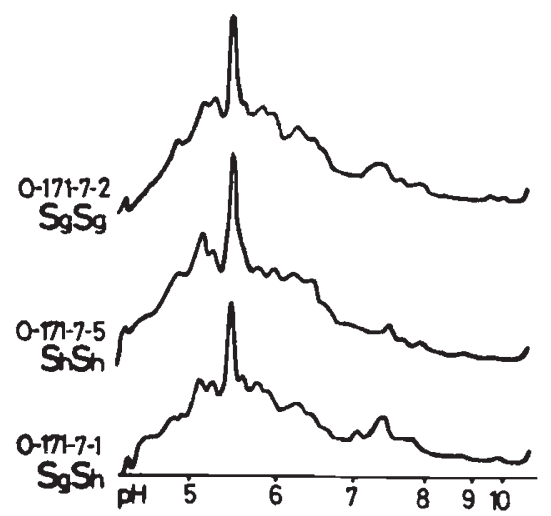

Fig. 3.-Data of the diallel pollinations (a) and of densitometries (b) in family O-171-7. Explanation as in fig. 1 .

(iii) Families $0-171-2,-5,-15,-18$ and $C-470-30$

In these families, one or more PAS-positive bands were ascribed to one $S$ allele, but no other bands were found ascribable to the other $S$ allele.

Family C-470-30 seems to be a similar case as regards $S$ alleles, but showed another glycoprotein peculiarity. We detected three differential protein bands, $\mathrm{B}_{6}, \mathrm{~B}_{7}$ and $\mathrm{B}_{8}$ in the family (fig. 4). Of the three bands, one $\mathrm{B}_{8}$ was ascribed to the $S_{e}$ allele. Bands $\mathrm{B}_{6}$ and $\mathrm{B}_{7}$, however, segregated independently of the $S$ alleles. They seemed to be controlled by a pair of allelomorphs, since no plant lacking both bands has yet been observed. All three bands were PAS positive. So far, we have not found any other glycoprotein ascribable to the other allele, $S_{d}$.

$$
41 / 1-_{\mathrm{G}}
$$



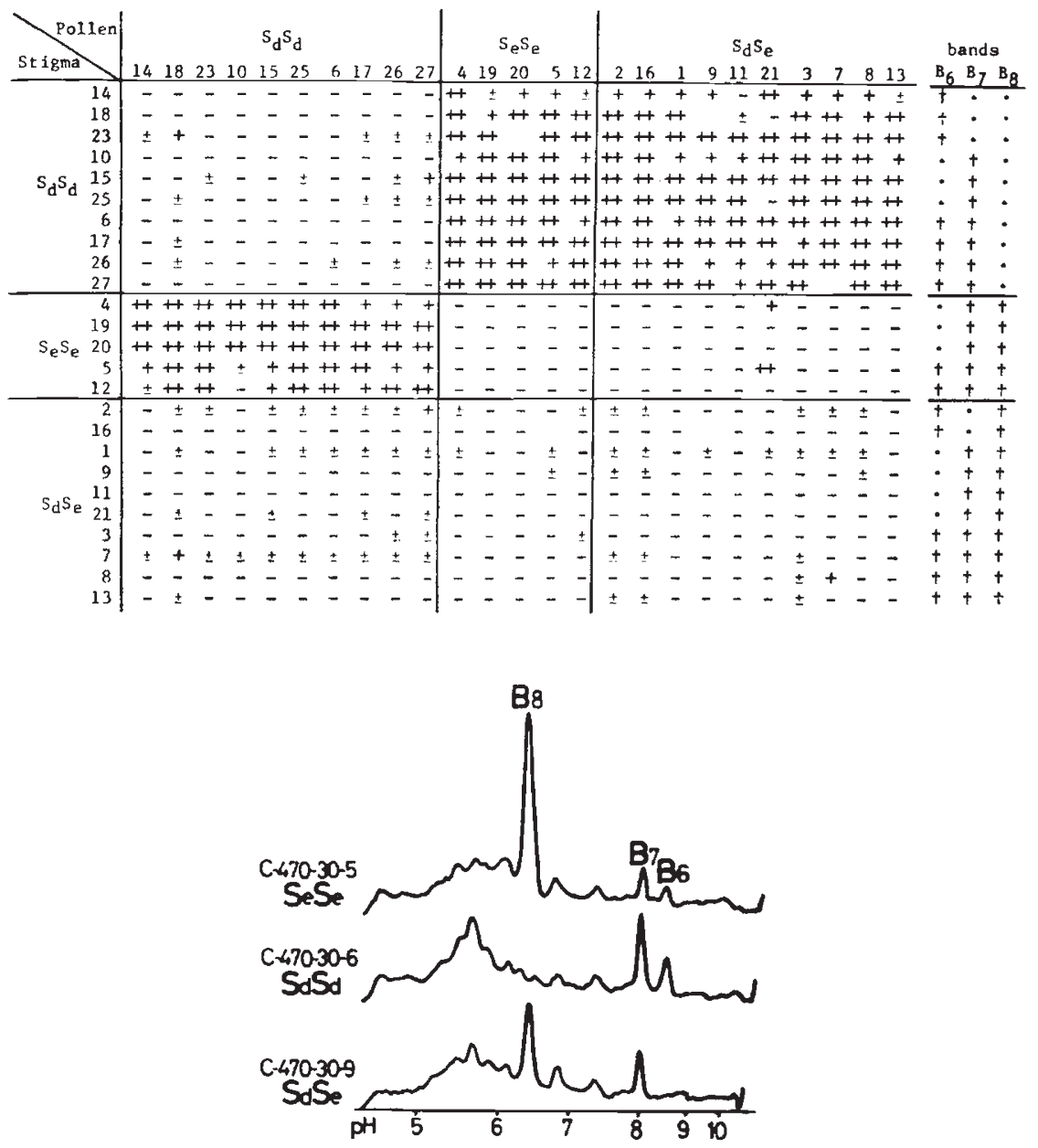

Fig. 4.-Data of the diallel pollinations, of the differential bands (a) and of densitometries (b) in family C-470-30. Explanation as in fig. 1.

During the investigation of family O-171-15, the band of one $S$ allele was thought to correspond to the band $\mathrm{B}_{3}$ of the $S_{a}$ allele in the family O-171-23 (fig. 1). It was ascertained from a pollination experiment that these alleles were cross incompatible (i.e. identical).

\section{Discussion}

Self-incompatibility in Brassica species is due to the inhibition of pollen tube penetration into stigma tissues in illegitimate pollinations. The pollen tube penetration was, therefore, examined to determine $S$ genotypes in a family. The sporophytic control of a pair of $S$ alleles was generally confirmed, though an exceptional case in the family O-171-23 is being further investigated.

Adding up the total $S$ alleles of seven families, 13 were investigated since two were thought to be identical. Glycoprotein bands completely cor- 
related with seven $S$ alleles were found, but no protein bands ascribable to the other six alleles have been detected so far. The differential proteins may correspond to those which were detected by immunological techniques. The data indicating that the differential proteins appear in mature stigmatic tissues (Nishio and Hinata, 1977a) and that the content of the differential proteins in homozygotes was roughly twice as much as in heterozygotes are comparable to those reported by Nasrallah (1974) and Sedgley (1974b), respectively. Nasrallah et al. (1972) studied correlations between three $S$ alleles and antigens or disc electrophoretic bands. One band was ascribed to the $S_{2}$ allele but no detected bands were ascribed to $S_{1}$ and $S_{3}$. Presence of a segregating band independent of $S$ alleles was also indicated. These were supported by our observations with a number of $S$ alleles.

As for the $S$ alleles to which no detected proteins were ascribed, two alternative possibilities should be considered. The first is that certain glycoproteins were unable to be extracted or detected by the present method. Cases could be imagined in which some kinds of glycoproteins strongly bound to cell membranes, or undetectable amounts of proteins, were enough for the actual recognition events, and so on. The other possibility is that these $S$ alleles do not produce any specific proteins and that the $S$-correlated proteins are not essential to self-incompatibility reactions. Although we do not support this latter alternative, it cannot be ruled out until further studies have defined the role of the $S$-correlated glycoproteins in the self-incompatibility mechanism.

All the differential protein bands were PAS positive and no other prominently PAS-positive bands were observed in the present study. Of these differential glycoprotein bands, two, $B_{6}$ and $B_{7}$, were not correlated with $S$ alleles, while all the other bands were so correlated. The proteins differentiating $S$ homozygotes have all been taken into account in our previous speculations on $S$ specificity. They may, however, include both $S$-determined proteins and ones not determined by $S$. Only the $S$ correlated glycoproteins would then be candidates for $S$-specific substances.

In some cases two glycoprotein bands were ascribed to one $S$ allele. This may suggest a possibility that the $S$ alleles denoted here are complex genes as mentioned in a previous report (Nishio and Hinata, 1977a). Another possibility is that one band is the dimer of the other. A preliminary observation suggests that a specific band may be separated into two or more fractions by SDS electrophoresis or by isoelectric focusing in the presence of urea (unpublished). The chemical analysis of the specific glycoproteins is now in progress, and they seem to be complex in nature.

Self-incompatibility has been widely used to obtain hybrid seeds in the breeding of Brassica species. The identification of $S$ alleles could be of practical value. The analysis of the specific proteins might be expected to help this work. For example, the identity of two $S$ alleles in different families was suggested by isoelectric focusing, and confirmed by pollinations. When glass tubes of $3 \mathrm{~mm}$ diameter were used in isoelectric focusing, 10 stigmas per individual were enough for the identification of the specific proteins. The present limitation is that no specific proteins have found corresponding to some $S$ alleles.

Acknowledgments.-The authors are indebted to Prof. S. Tsunoda, Tohoku University, for valuable advice and encouragement. Thanks are also due to $\mathrm{Dr} \mathrm{A}$. J. Bateman for critical reading and correcting the manuscript. 


\section{REFERENCES}

Bateman, A. J. 1955. Self-incompatibility system in Angiosperms. III. Cruciferae. Heredity, 9, 53-68.

DICKINSON, H. G., AND LEWIS, D. 1973. Cytochemical and ultrastructural differences between intraspecific compatible and incompatible pollinations in Raphanus. Proc. R. Soc. Lond. B., 183, 21-38.

FAzeKAS DE ST. GRoTh, s., Webster, R. G., AND DATYNeR, A. 1963. Two new staining procedures for quantitative estimation of proteins on electrophoretic strips. Biochm. Biophys. Acta, 71, 377-391.

haruta, T. 1962. Studies on the Genetics of Self- and Cross-incompatibility in Cruciferous Vegetables. Northrop, King and Co., Minneapolis, pp. 67.

KANNO, T., AND HINATA, K. 1969. An electron microscopic study of the barrier against pollen tube growth in self-incompatible Cruciferae. Plant and Cell Physiol., 10, 213-216.

KROH, M. 1964. An electron microscope study of the behavior of Cruciferae pollen after pollination. In Pollen Physiology and Fertilization, ed. H. F. Linskens, pp. 221-224. N. Holland Publ. Co., Amsterdam.

KUČERA, V., AND POLÁK, J. 1975. The serological specificity of $S$ alleles of homozygous incompatible lines of the marrow-stem kale (Brassica oleracea var. acephala DC.). Biol. Plant., 17, 50-54.

NAKANISHI, T., AND hiNATA, K. 1973. An effective time for $\mathrm{CO}_{2}$ gas treatment in overcoming self-incompatibility in Brassica. Plant and Cell Physiol., 14, 873-879.

NASRALLAH, M. E. 1974. Genetic control of quantitative variation in self-incompatibility proteins detected by immunodiffusion. Genetics, 76, 45-50.

NASRALlaH, M. E., BARBER, J. T., AND WALlACE, D. H. 1970. Self incompatibility protein in plants: detection, genetics and possible mode of action. Heredity, 25, 23-27.

NASRALlAH, M. E., AND WALlACE, D. H. 1967. Immunogenetics of self-incompatibility in Brassica oleracea L. Heredity, 22, 519-527.

NASRAllah, M. E., Wallace, D. H., AND Savo, R. M. 1972. Genotype, protein, phenotype relationships in self-incompatibility of Brassica. Genet. Res., Camb., 20, 151-160.

Nishio, T., AND hinata, K. 1977a. Analysis of $S$-specific proteins in stigma of Brassica oleracea L. by isoelectric focusing. Heredity, 38, 391-396.

NISHIo, T., AND HINATA, K. $1977 b$. Positive PAS reaction of $S$-specific prote ins in stigma of Brassica oleracea L. Incompatibility Newsl., 8, 31-33.

NISHIO, T., AND HINATA, K. 1978. Stigma proteins in self-incompatible Brassica campestris L. and self-compatible relatives, with special reference to S-allele specificity. $\mathcal{F} a p .7$. Genet., 53, 197-205.

SEDGLEY, M. 1974a. Assessment of serological techniques for $S$-allele identification in Brassica oleracea. Euphytica, 23, 543-551.

SEDGLEY, M. 1974b. The concentration of $S$-protein in stigmas of Brassica oleracea plants homozygous and heterozygous for a given $S$-allele. Heredity, 33, 412-416.

тномpson, K. F. 1957. Self-incompatibility in marrow-stem kale, Brassica oleracea var. acephala. I. Demonstration of a sporophytic system. 3. Genet., 55, 45-60.

ZACHARIUS, R. M., ZELL, T. E., MORRISON, J. H., AND WOODLOCK, J. J. 1969. Glycoprotein staining following electrophoresis on acrylamide gels. Anal. Biochem., 30, 148-152. 